\title{
Re-Fashioning Fashion: An Exploratory Study of a Live Audio Described Fashion Show
}

\author{
J. P. Udo
}

Ryerson University

Deborah I. Fels

Ryerson University

Udo, J. P., \& Fels, D. I. (2010). Re-fashioning fashion: An exploratory study of a live audio-described fashion show. Universal Access in the Information Society, 9(1), 63-75.

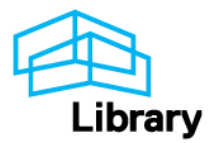




\title{
RE-FASHIONING FASHION: AN EXPLORATORY STUDY OF A LIVE AUDIO DESCRIBED FASHION SHOW
}

\author{
Post-refereed version. \\ This paper is available in the Online First section of the Universal Access in the Information Society journal. \\ It can be found at \\ $\mathrm{http}: / / \mathrm{www}$. springerlink.com/content/107725/?Content+Status=Accepted\&sort=p_OnlineDate\&sortorder $=\mathrm{desc} \& \mathrm{v}=$ \\ condensed\&o $=10$
}

Udo, J.P. \& Fels, D.I. ${ }^{1}$

J.P. Udo, M.A.
Ryerson University
350 Victoria Street
Toronto, Ontario
M5B 2K3
Deborah I. Fels, PhD., P.Eng.
Ryerson University
350 Victoria Street
Toronto, Ontario
M5B 2 K3
dfels@ryerson.ca
T: 4169795000 ext 7619
F: 4169795249

Total number of words: 7,753

Keywords: Live audio description, access to live content for people with vision impairments. 


\title{
FOOTNOTE PAGE
}

\author{
${ }^{1}$ Contact Author
}

Acknowledgments

Funding for this project was generously provided by CulturAll and Canadian Heritage, and NSERC \# 184220-05. We also thank all of the Mass Exodus staff and students for their support and willingness to try something new. We are grateful to all of the students and staff at the Centre for Learning Technologies at Ryerson University, and the Adaptive Technology Resource Centre at the University of Toronto who made this project possible. Thanks to Lisa Copeland for editing assistance. Finally, we thank all of the blind, low-vision and sighted people who participated in this research. 


\begin{abstract}
We present a process and its analysis for live audio description of a fashion show that contained only music and no dialogue. Our findings suggest that using a content expert with a process that combines conventional audio description techniques with colour commentary techniques to allow emotion and excitement as well as description of the important visual elements is enjoyable and entertaining for blind, low-vision and sighted audiences. In addition, we found that about 60 percent of the content of the live show could be described in a timely manner. Finally, we found that the describer added about three times as many descriptions from a prepared script as were omitted.
\end{abstract}

\title{
INTRODUCTION
}

The social and cultural discourses that entertainment media provides helps to shape and define us as a society. It is so ubiquitous that individuals who are unable to equally participate can be isolated from or experience distinct disadvantages in access cultural and social activities. Within the low-vision and blind communities, equal access to and, hence, participation in live events which are often dominated by visual presentations (e.g., theatre, parades, sports, fashion shows, etc.) and the discourses that they open up remain, for the most part, inaccessible. Individuals with vision impairments often have difficulty with understanding action occurring within a visual context, negatively affecting their ability to absorb a similar experience as their sighted peers. While a variety of audio description (AD) strategies have been implemented to make live events more accessible to blind and lowvision communities, there has been little research reporting the effects of these services.

\section{BACKGROUND}

The audio-only description of events exists in two separate contexts: accessibility and athletics. One type of audio description first arose through the advent of the radio. Listeners could tune into a sporting event, experiencing it via the descriptions and commentary of a radio broadcaster who was present at the event. The information conveyed through this kind of commentary, however, is usually far more useful for people who have knowledge of the sport and the teams that are playing than those who have never seen the sport being played, or had it properly explained to them. 
Within the context of accessibility and assistive technologies, audio description provides individuals with vision impairments access to verbal descriptions of some (but not all) visual information. These aural descriptions are inserted in the non-dialog spaces (during silent, music-only, or minor sound effects occasions) of film, television, or live content (National Centre for Accessible Media, 2003; Wall, 2002). Without access to AD, individuals with vision impairments remain at a unique social disadvantage, as they are unable to fully participate in a culture that is heavily saturated by and based on the enjoyment of audiovisual entertainment experiences (Packer \& Kirchner, 1997).

Audio Description Associates (n.d.) and the National Center for Accessible Media (2003) provide a very thorough description of the guidelines and conventions for the $\mathrm{AD}$ of live and post-production content. Their suggested approach/strategy supports the notion of the camera lens metaphor which was developed by G. Frazier in the 1970s and expanded upon by Pfanstiehl and Pfanstiehl in 1980s (Synder, 2004). Adhering to this approach, the describer is meant to be an objective interpreter and translator of the important visual events, costumes, scenes, and effects that cannot be disambiguated through sound. Describers are encouraged to use precise but highly descriptive language, a strategy recommended regardless of venue or genre. There are also some limited variations regarding the timing of description with their corresponding visual events within this common approach. For example, some description services allow for descriptions to occur sometime before or after the actual visual event being described while others insist that the description should occur at the same time as the visual event being described.

For live events, the quality and quantity of description is primarily dependent upon the event and the length of the show's engagement at a theatre. In the United Kingdom and the United States of America, many theatres offer audio description for theatrical events. However, the availability and delivery of live description services varies from theatre to theatre, although, for the most part, it is often severely limited to very specific show times and dates where audio describers can be scheduled. Alternatively, Kennedy Centre for the Arts (n.d) schedules AD by request, although two weeks notice is required.

However, the accurate and seamless description of live events requires commitment of more time and resources than most budgets normally allow. For example, the describer must become familiar with the entire production, including the script, playwright, historical backdrop, the director's intended message, acting style, music, and other factors in order to determine the optimal description. In addition, there is little research that provides guidance on how to produce efficient and effective $\mathrm{AD}$.

Theatres must also invest in AD hardware (ear pieces, microphones, etc.) and facilities (the construction of a booth, promotional displays, etc.). The AD is then broadcast through the system to wireless headsets that audience members wear. Only audience members wearing headsets receive the descriptions.

Some non-profit organizations like Audio Description Associates (n.d.), Arts Access Inc. (n.d.), Arts and Visually Impaired Audiences (n.d.), The Metropolitan 
Washington Ear (n.d.) use volunteers to provide AD for one or two select theatre performances, often requiring a brief audition (Audio Description International, n.d.; National Theatre, n.d.) and/or training (Hospital Audiences Inc., n.d.). Some theatres find their own volunteer describers (Pitlochry Festival Theatre, n.d.; Centerstage, n.d.).

Others take an open description approach where the description is available to all audience members. For example, Extant, a theatre company in the UK made up of visually impaired performers, wrote the AD for their production "Resistance" as part of the original the script. This then alleviates the need to hire or find outside describers (British Council for the Arts, n.d.).

Several theatres and theatre companies offer additional services for blind and lowvision audiences: a live (The Royal Lyceum Theatre, n.d.; Guthrie Theatre, n.d.) or recorded (English National Opera, n.d.) AD of program notes, an audio version of season brochure (The Royal Court Theatre, n.d.), large print program (Cumbernauld Theatre, 2003), and pre-performance touch/sensory tours where blind and low-vision individuals are invited to feel the sets, props, and costumes used during the show (Orange Tree Theatre, n.d.; The Royal National Theatre, n.d.; The Royal Shakespeare Company, 2006; Derby Playhouse, n.d.; Birmingham Hippodrome, 2006).

$\mathrm{AD}$ for long-term performances has the potential to be more financially viable as the cost of making the event accessible can be recuperated over time, especially if the accessibility features offered do not require additional staff for each show. One company in the US, Sound Associates Inc., provides such a service. This company uses a similar process to that used in post-production $\mathrm{AD}$ for television and film the $\mathrm{AD}$ is pre-recorded and edited to fit the original sound track. It can then be played for every performance. This eliminates the need to schedule special described performances where a live describer is available.

Sound Associates produce their AD in house (Steve Harris, Director of Sales and Operation, New York Office, Sound Associates, personal communication, August $23,2006)$. The person who writes the descriptions often records them after having watched the show and authored an "AD script". The author is seldom trained in $\mathrm{AD}$ or theatre arts. The ADs are recorded as digital files and then made into short audio clips. These clips are then queued to be triggered as lighting cues from the lighting board as controlled by the lighting technician.

Because the shows are live, there can be slight changes in the timing or errors that occur. The description timing can be adjusted to account for these differences because the lighting technician can make slight timing alterations or description omissions to accommodate them. For example, if an actor makes her entrance late, the description which explicitly notes her entrance could be delayed or even omitted by lighting technician. In some cases, additional lighting cues (where no lighting changes actually occur) are created to ensure that descriptions are synchronized properly to the live action on stage. The advantages of this type of services are that it can be reused for all performances of a long running show. However, the disadvantages are that the describer has little investment in the event on an on- 
going basis, there is little spontaneity that is normally associated with live theatre, and there has been little research on the entertainment value of this type of description.

Research carried out by Pettitt, Sharpe \& Cooper (1996), Peli \& Fine (1996) and Schmeidler \& Kirchner (2001), showed that AD had positive outcomes for television viewers. They found that AD provided comprehension, enjoyment, and cultural participation benefits to people with vision impairments, and that people preferred watching television with AD than without it. Peli \& Fine (1996) also found that sighted viewers experienced benefits from the ADs, positively affecting their comprehension level of a television program. Fels et. al. (2006) compared a first person narrative style of $\mathrm{AD}$, where the main character of the show presented $\mathrm{AD}$ in first person, with the more conventional $3^{\text {rd }}$ person AD style. They found that viewers reported that the first person version was less trustworthy but preferred it anyway because it was more entertaining. A question then arises regarding the entertainment and information expectations and desires of vision impaired audiences.

All of this research was carried out for pre-programmed television; no live content with or without description was considered. However, considerations of presentation style, voice, emotion, and other artistic characteristics may play an important role in providing more equivalent experiences of cultural content (live or programmed) for people with vision impairments.

In on-line environments, there are some guidelines for $\mathrm{AD}$ provided in the $\mathrm{Web}$ Content Accessibility Guidelines 1.0 (WCAG) (W3C, 1999) but these mostly relate to post-production video materials rather than to live webcasts. It also appears that considerations are being made to move $\mathrm{AD}$ from a checkpoint (checkpoint 1.2) to a best practices section meaning that is it only a recommendation rather than a requirement for web-based pre-recorded video. In the most recent working draft of WCAG 2.0 (W3C, 2008), AD is part of guidelines 1.2.2, 1.2.4 and 1.2.6 meaning that it is again appearing as a web accessibility requirement rather than only a recommended best practice. However, there is no requirement for audio describing live video content which may be due to the popularity of webcams, live webcasts, and the difficulty and lack of process/guidelines available for providing live descriptions.

The widespread adoption of sports broadcasting via radio did not arise out of a desire to accommodate individuals with disabilities, but rather to include remote participants. While AD for people who are blind and low-vision tends to be highly factual, sports commentary adds an emotional element. Hansen (1999) argues that two forms of talk exist within sports commentary: "play-by-play, a description of the ongoing action, and colour commentary, a narrative composed of background information and interpretation of the action" (269-70). While the play-by-play is similar in style to AD in that it provides an aural description of visual events, colour commentary is infused with emotion. According to McGuire (2002), a basketball announcer must possess specific skills to be successful. They must be prepared and familiar with the teams, the roster as well as individual and team 
statistics. Commentators should be able to aurally describe what is visually occurring on the court, giving listeners an up-to-date picture of what is occurring on and off the court. McGuire argues that announcers must capture the excitement of the game for their listeners and translate it, through their choice of words and their delivery, to their listeners. It is the excitement of the game combined with the factual information that provides the entertainment value of sports commentary. We suggest that an alternative approach to the conventional form of AD where emotive elements would be included within the description would prove beneficial. In addition, we hold that $\mathrm{AD}$ should be considered as an integral creative element of the narrative.

In this paper, we present the techniques used and the data collected from one live described fashion show, Ryerson University's Mass Exodus 2006: Open Concept. The show was also webcast for a live on-line audience. As part of this event, we explored the use of a description style that blended conventional $\mathrm{AD}$ techniques with colour commentary techniques in a live context in order to affect the entertainment value of the show for blind and low-vision audiences. We present a description of the live description technique used for the fashion show and the subjective audience reaction data that was collected from sighted and vision impaired live and on-line audiences.

\section{MASS EXODUS AND THE LIVE DESCRIPTION PROCESS}

Each year, Ryerson University's School of Fashion hosts a premiere fashion show which runs for three days. This show is a venue for graduating students to display their collections for the public as well as members of the fashion industry. Throughout the production of this year's fashion show, concerns regarding the accessibility of the event began to surface, leading to the development and incorporation of devices and services that would enable blind/low-vision, deaf/hard of hearing and remote users the opportunity to fully experience the fashion show through the use of assistive technology.

Without the presence of a describer, the fashion show would have been completely inaccessible to individuals with vision impairments as, apart from the opening speeches, the show contained only music and no dialogue. The show's extremely limited engagement required that any $\mathrm{AD}$ had to be provided live instead of preproduced.

\section{METHOD}

This study was primarily concerned with the impact of the description process on the describer. In order to provide description with a focus on entertainment rather than information, and according to earlier research on the requirements for live 
AD (Branje, et. al, 2006), we believed that the describer for the fashion show had to be knowledgeable and passionate about the event she was to describe. As a result, an upper year student from the fashion school who had been involved in producing the previous years' show was selected. This student also had theatre training from a previous university degree, making her an excellent fit for the describing task as she had an in-depth knowledge of the fashion, was a mature upper year student, knew many of the fashion students personally, and knew how to control her voice according to standard theatrical practices. The describer was asked to keep a journal detailing the process that she went through to form the description script, including interviews, collection notes, and her own thoughts.

The information gathering process that the describer followed included: attending a three-hour $\mathrm{AD}$ workshop, interviewing students about their collections, and participating in production meetings with the organizers, and technical crews. From there, she was able to write notes for each collection and make decisions about what to say, how to say it and what could be left out. During the first performance of the show (which was not described), the describer was able to run a "description dress rehearsal" to practice.

To ensure that she did not interrupt other audience members during the actual described show, the describer was positioned at the back of the theatre, beside the webcast and audio booth, and located within a sound-proof enclosure. She was able to watch the show through a large window facing the stage. The describer had her own light, note stand, and stool. A microphone in the enclosure relayed the $\mathrm{AD}$ from the describer through a wireless FM loop to the earpieces of those audience members who expressed interest in hearing the show described. Feedback from those listening to the $\mathrm{AD}$ of the live event was not available to the describer at any point before, during or after the performance. These comments, therefore, did not affect the describer's modifications throughout the performance.

For the fashion show, there were 283 outfits that were shown by 59 designers (approximately five to seven outfits each), of which the describer prepared description notes for 187 outfits ( 66 percent). There was little research to guide the number of outfits that could reasonably be described, and the researchers and describer believed that describing all outfits would result in cognitive overload and fatigue because there was a new outfit appearing every 15 seconds. It would have been difficult for the describer to accurately communicate the complexity of each outfit shown on stage in that 15 second window, every 15 seconds for the entire show lasting one hour and forty-five minutes. As a result, we estimated that 66 percent would be a reasonable compromise.

The researchers and the describer also wanted to create description that was conducive to the "laissez faire" and playful attitude of a fashion show. To communicate this feeling, the describer included background information of each designer's collection which focused on their inspiration for their collection. This added time to the collection description so that it would not be possible to describe each outfit before the next collection appeared. 


\section{DATA ANALYSIS}

Very little research on the use and measurement of live AD has been published. Looking to the data, we wanted to understand the types and quantities of variations made between prepared $\mathrm{AD}$ notes/script and the $\mathrm{AD}$ offered up during the describer's actual performance.

To this end, two researchers analyzed the variations between the describer's AD script and the description provided for the actual performance. Sutcliffe \& Rugg (1998) provide a taxonomy of error types which researchers used to determine the variations to analyze.

Three major variations, Commission, Omission, and Other, and several subvariations were identified and defined. Commission variations occurred when a description was added to script, while Omission variations occurred when something was left out. Other variations arose when there was a combination of Omission and Commission variations occurring together or a variation that was neither commission nor omission (e.g., word substitution).

Commission variations were further classified into four sub-categories: general improvisations, description improvisations, order descriptions and error misspeaks. A general improvisation was defined as the addition of a comment that was not directly related to the description of clothing or action occurring on stage. General improvisations did not provide any narrative or descriptive function (e.g., "wahoo!" and "ah, I wish I had time to describe them another one!"). Description improvisations, however, directly related to the onstage action and/or assisted in bettering understanding (e.g., "model turns her back to the audience to reveal ...") or where personal opinions were inserted (e.g., "I don't really see how they can see their way down the runway").

Order descriptions were noted when the describer clearly verbalized a transition to the description of a different model (e.g., "the next model is wearing..." or "a man wearing..."). These descriptions were unrelated to the specific outfit being shown. Error misspeaks were defined as the describer's verbal deviation from the intended meaning of her notes or when she said something that was incorrect (e.g., "there are five dancers...oops, I mean four!"). Error misspeaks are further subcategorized into those that were verbally corrected and those that were not verbally corrected.

Variations of omission were also divided into three sub-categories: unused background notes, partial description, and model omitted. Unused background notes occurred when the describer did not include notes she made about a collection prior to the show in her live AD. Background notes were included within the script as bullet points, ranging from two or three words (e.g., "all silk including lining") to a sentence (e.g., "the girls believe there's a need in the market for fun formal wear for petite women because the designers themselves have trouble finding clothes"). Partial description occurred when the describer was unable to include the description of an entire outfit and tended to be only a few words long 
(e.g., "poufy, short capped sleeves"). Model omitted was used when the describer did not describe a model for which she had a prepared description.

There were also some variations that included elements of commission and omission. Incorporation of notes occurred when the describer took a previously omitted collection summary point from her notes and incorporated it into the actual description of another outfit. Word substitution occurred when the describer substituted one word for another ("tough like the boys" instead of "just like the boys"). Description error in notes occurred when the notes deviated from what has happening on stage (notes read "top is strapless", yet during performance describer corrected herself "oh no, it's got straps, just kidding!").

\section{RESULTS}

\section{Describer Variations Analysis}

A $\chi^{2}$ analysis of variations in the Omission and Commission categories shows a significant difference between all of the sub-categories, (omission categories: $\chi^{2}(2,468)=61.34$; commission categories: $\left.\chi^{2}(3,468)=65.59, \mathrm{p}<0.05\right)$; and between the commission and omission categories: $\left.\chi^{2}(1,468)=82.09, p<0.05\right)$. Figure $1-3$ shows the number of occurrences of each variance type. There were a total of 332 Commission variations, 136 Omission Variations, and 15 Other variations made to the 492 description notes in the script.

Commission variations included: General Improvisations, Description Improvisations, Order Descriptions and Error Misspeaks. The describer added 56 General Improvisations. Description Improvisations and Order Descriptions contained the highest number of occurrences (136 and 98 occurrences respectively). There were 42 instances of Error misspeaks, 28 of which were verbally corrected.

The most frequent Omission variation, Unused Background Notes, occurred 88 times, while Partial Description Omissions occurred 25 times. Eighteen model descriptions were completely omitted.

The fewest variations were made in the Other category which included five word substitutions, seven incorporation of notes and two error in notes. In general, occurrences of variations in the Other category were considerably lower than those in the Omission or Commission categories. 


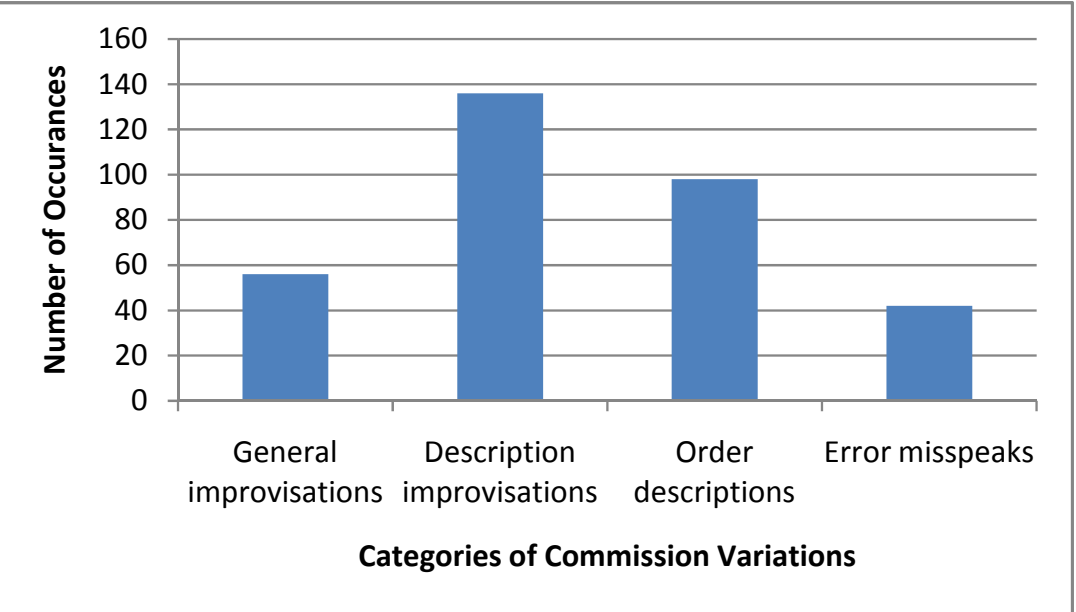

Fig. 1. Commission Variations

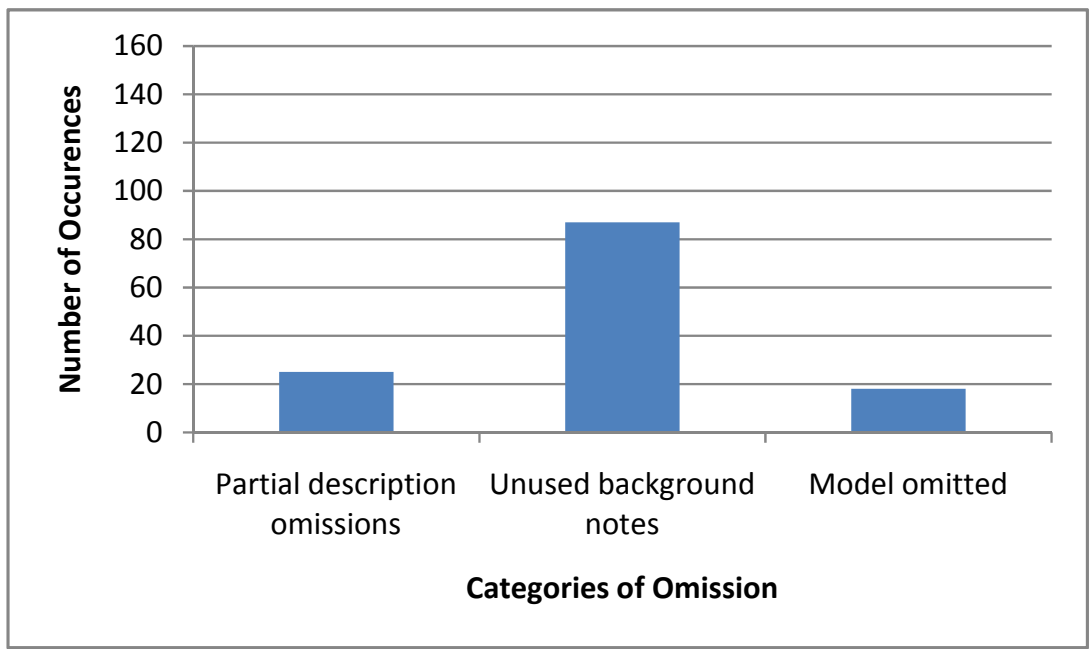

Fig. 2. Omission Variations 


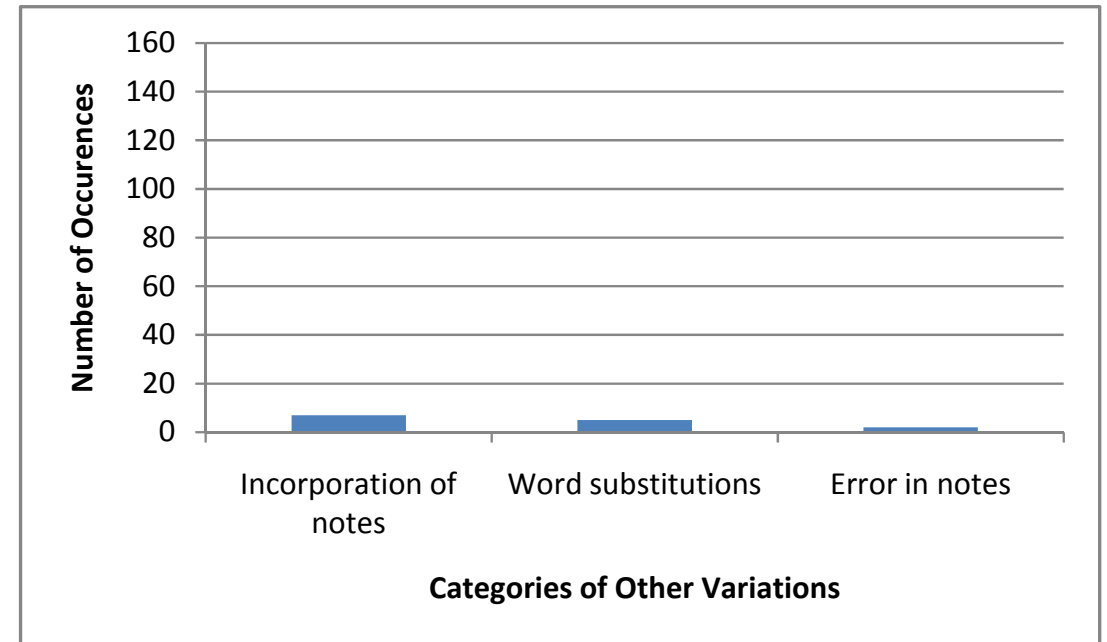

Fig. 3. Other Variations

A correlation was applied to the variation data to examine the distribution of Commission and Omission variations over the collection order (time). As the Other category of variations contained relatively few numbers of variations compared with the other two main types, they were removed from this analysis. There was a positive and significant correlation between the number of commission variations and the time $(\mathrm{r}(55)=0.31, \mathrm{p}<0.05)$. There was a negative but non-significant correlation for omission variations $(r(55)=-0.12, p>0.05)$. Figures 4 and 5 show the distribution of omission and commission variations for all collections in the show respectively. 


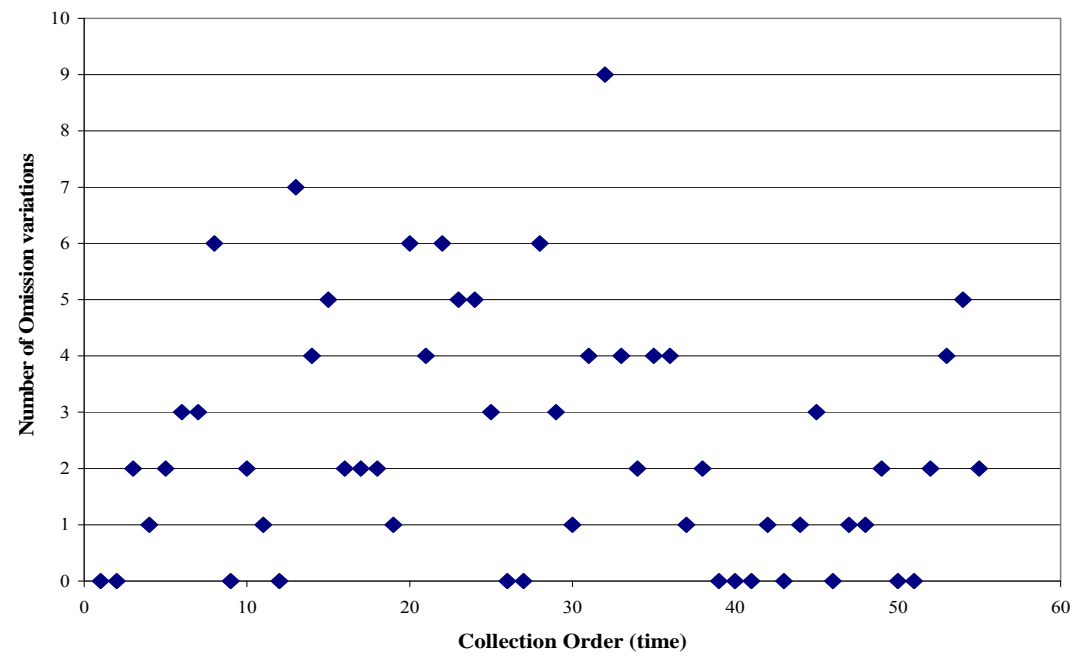

Fig. 4 Distribution of Omission Variations Over Time

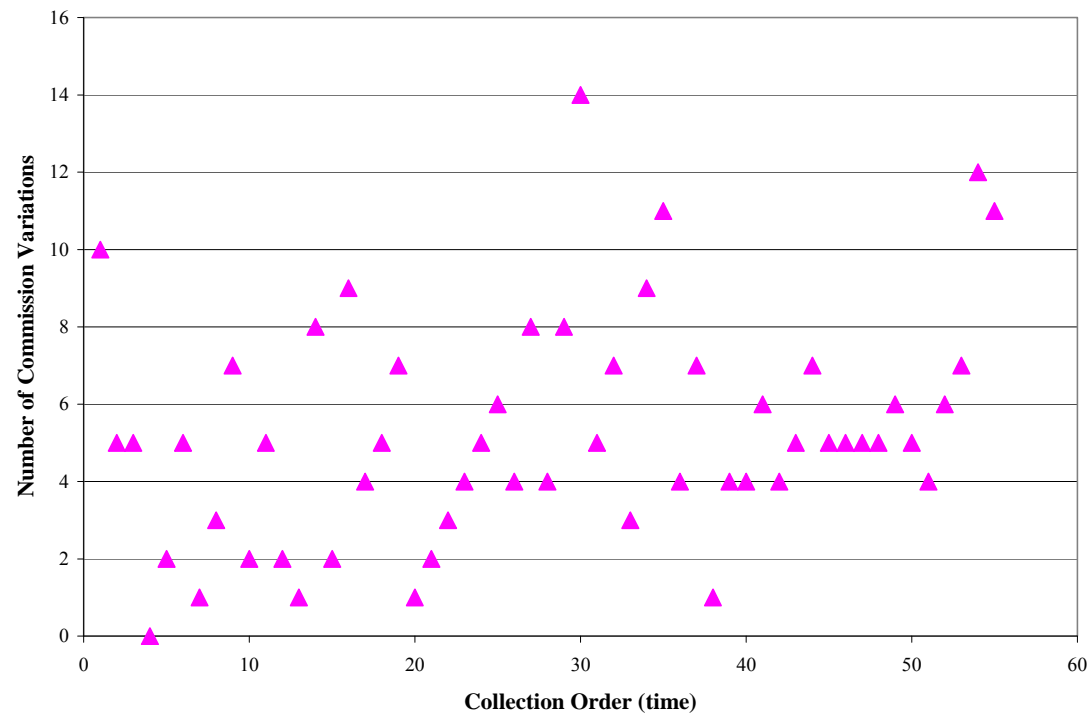

Fig. 5 Distribution of Commission Variations Over Time 


\section{Direct Feedback from Sighted and Vision Impaired Live Audience Members.}

To obtain feedback from participants, an online and face-to-face survey was conducted. All participants present at the fashion show were asked to individually respond to 11 questions pertaining to description quality (technical quality, speed, language level, and style), entertainment value of fashion show, and of the description (strengths, weaknesses, and understandability). The online version of the questionnaire was similar except that it related to the webcast instead of the live show. Sighted audience members were also asked similar questions as well as some additional information about any previous experience with AD. Blind audience members were asked these demographic questions prior to the show as they were known a priori. Sighted audience members were ad hoc and expressed interest in listening to the live description once at the show. Some of the sighted audience members were companions of those who were blind.

All blind audience members were interviewed for about 15 minutes immediately following the show and the sighted audience members completed a written version of the questionnaire.

There were three blind audience members, two male, one under the age of 18 and one in the 35-55 range, and one female, in the 35-55 range, who attended the show. All three people reported being entertained by the fashion show and two people reported that the describer "brought the fashion show to life" and filled in details. Two people reported that the ambient music for the fashion show was too loud and interfered with their ability to hear the describer. Two people reported that they liked the describer's enthusiasm and emotion, and the extra details that she provided such as the motivation behind each designer's collection. One person wanted just the description without the emotion but still reported that they liked the style. Finally, one person suggested that describers should be careful about using visual terminology to describe a visual scene but instead use metaphors from other senses (e.g., colour as a feeling). All three people suggested that they would be comfortable conversing with sighted people about the show and that the description provided would facilitate their discussion.

There were four female and one male sighted audience members who completed a questionnaire. There were two people between 50 and 59 years, one person who was over 60 years, one person in the 40-49 age group and one person in the 30-39 age category. Only one person of these five had any experience with $\mathrm{AD}$, listing it as seldom used. Three of the five said that they were somewhat entertained by the fashion show itself and two said they were very entertained indicating that their experience at the fashion show was positive. When asked specifically about the $\mathrm{AD}$, two people stated that they were very entertained while one person was somewhat entertained and one other was only a bit entertained by the descriptions (one person did not rate this question). Reasons that influenced this level enjoyment related to the high volume level of the music track, similar to that reported by the vision impaired audience members. Seating for most of the study partici- 
pants was assigned to the front row very near the main speakers that played the music for the show, and it was indeed very loud. One person stated that the description style with the "affective content" added to her enjoyment of it. However, another person found it distracting and did not seem to like that the describer added her own comments. Responses to specific questions about the quality of the elements of the description varied but all of them were positive. All sighted subjects stated that the speed of the description was good or very good. Two people rated the technical quality (e.g., sound level, voice, volume level) as good, one as very good and one as neutral. Three people rated the description quality (language level, terminology, and errors) as neutral and one as very good. Finally, two people rated the style of the description (emotional content, etc.) as very good, one as good and one as alright. One person had difficulty with the sound levels and did not answer these questions. Two people said that the description helped them a lot in understanding the fashion show, one as somewhat helpful and one as a bit helpful. When asked to identify weaknesses, people reported that there was too much detail and that the describer made errors, such as saying "um" too often. However, when asked to identify the strengths, all of the respondents enjoyed the style, the emotion, and the enthusiasm of the describer. Most reported that they very much enjoyed the description, one person even reported that she had a very good first experience with live description.

\section{Feedback from Webcast Participants}

By coincidence, all five participants who watched the fashion show via web broadcast were low-vision, while all participants attending the fashion show live were blind. After watching the fashion show, webcast participants completed a feedback questionnaire. All participants were female with two being in the 19-29 age range, one in the 30-39 range, one in the 40-49 range and one in the 60+ range. Four people reported that they were very interested in the fashion show and one reported that it was not very interesting. Three people found that the description was very entertaining, while two found it not very entertaining. Two people found the speed of the description as too slow, two found it just right, and one found it too fast. Three people found that the description was good quality, where quality for live description was defined as the number of errors audience members noticed and the completeness of the description. Two people found it as low quality. Three people reported that they liked the style of the description better than on television, one did not like the style and one thought is was ok but liked the television style better. In the feedback questionnaire people were also asked to provide written comments on the strengths and weaknesses of the show. Two people commented on the need to improve the technical quality of the video/audio cast (the video was grainy when enlarged, sound was somewhat muffled). One person reported that she "thoroughly enjoyed the show" and one person suggested that the describer should have been more "professional". 


\section{DISCUSSION}

Comparing the describer's script with the verbal descriptions voiced during the actual performance of the fashion show provides some interesting insight into the process of planning and delivering live description. We have also begun to understand the types and frequency of script variations, and their impact on audiences. Frequency analysis of the variations and the questionnaires provide data through which to identify aspects of the fashion show that were especially strong as well as those that needed improvement. Audience feedback also provides researchers with important qualitative data. However, the describer was not privy to these comments and, therefore, any improvisations or omissions made to the script during the performance were not influenced by audience input.

Early on, the research team and the describer decided that it would be too rushed to describe everything that was occurring on stage, especially since most collection featured five outfits and each collection was shown in less than one minute. When collections were created by two designers, seven outfits were created. However, only four collections featured two designers. For these four collections, the describer generally described one or two additional outfits. Focusing on quality rather than quantity, the team started with the goal of describing 60 percent of the outfits. The final version of the prepared description script included descriptions for 66 percent (187 of 283) of all the outfits.

During the described performance, 90 percent of the prepared descriptions were used (there were only 18 of the prepared model descriptions completely omitted) so about 60 percent of the outfits were actually described over a one hour and forty-five minute period (which was our initial target). From the questionnaire results, there were no complaints about the speed of the description from the live audience and two of the five online viewers (40 percent) found the description too slow, while only one found it too fast. For this particular fashion show, the feedback we received would illustrate that describing three out of five outfits was a satisfactory description speed.

Given this presentation rate, we expected that the describer would become fatigued as the show progressed resulting in more omission variations and fewer commissions variations from the notes. It was thus surprising to find a significant and positive correlation between the number of commission variations and time. The describer added more information to the outfits as time progressed.

The describer added 188 improvised comments during the show which were divided into those that related to the performance and those that did not. This division enables us to determine the frequency of comments contextually relevant to the fashion show.

If we examine the quality pattern of the show as subjectively identified by the describer, the commission variation pattern seems to somewhat follow a quality pattern of the collection presentation. She identified one collection at the beginning, five in the middle and two at the end of the show as being the highest quality. The describer was very excited by these collections and seemed to add more descrip- 
tion to emphasize the detail and complexity of these outfits and their presentation. In addition, she may have gained confidence in her abilities to add descriptions because her cadence and speaking patterns became comfortable and more practiced as the show progressed. One of the potential disadvantages of having describers add the emotive elements to their descriptions, particularly live descriptions, is that describer biases can be introduced. However, this also adds to the entertainment and excitement value of the description which, in this case, seemed to have been enjoyed by the audience members.

The describer added 132 of 188 (70 percent) improvised descriptions that directly related to the description of action on the stage and in the theatre. Hedrick (2000) argues that engaging colour commentary often takes into consideration the venue as a whole, including the venue itself and members of the audience. The describer for the fashion show provided improvised $\mathrm{AD}$, relaying visual events that were occurring onstage verbally so that those with vision impairments realised what was happening as the event unfolded. For example, when describing part of a fetish wear collection the describer added "I am not kidding" in a very playful tone when she described that the dress had "a hole in the back revealing bum crack and cheeks". The audience members seemed to appreciate these types of comments as most of the live and webcast audiences reported liking this style of description better than that seen on television.

Several visual onstage events prompted the entire audience to react audibly. Because blind or low-vision audience members lacked the ability to contextualize audio reactions to visual effects, the describer's awareness of these visual prompts was essential to ensure that their experience as spectators was inclusive. When audience members applauded as dynamic clothing features were revealed, the describer provided a verbal explanation that was not included in the prepared notes. For example, when a model dropped a hood that transformed into a train, the describer said "the audience is clapping because the model just dropped her hood to reveal...". When the visual cause of the audio effect was explained to listeners, they were then able to participate, for, although they were unable to see the event, they shared knowledge of the event itself. As unpredictable events occur at live events, even shows that are well-rehearsed, it is important that the describer be permitted to add descriptions to account for these events. In this particular show, the describer added 326 descriptions to the 492 planned ones with a majority (40 percent or 132 out of 326 ) of those additions being words or phrases.

In some cases, visual causes had no immediate audio reaction from the audience and, when this occurred, the describer explained the action. As part of a children's collection, five young girls were ushered onstage in flower girl outfits, the describer chose to account for their actions and those of the audience: "the girls are waving to the audience and the audience is waving back". Were they omitted and only the descriptions of the dresses themselves presented, low-vision and blind spectator's knowledge and experience of, and participation in the event as a whole, could have been considerably reduced. We believe that having descriptions for these types of spontaneous visual events added to the entertainment value of the show as a whole. 
Thirty percent of the improvised descriptions (97 out of 326 commission descriptions) were considered to be contextually unnecessary as they did not provide additional information about a specific outfit or were unrelated to the show itself. For example, in an explanation about the motivation for a particular collection, the describer said "bodies aren't uniform, why should underwear be" as indicated in her notes and then stated "she's right!" as an additional personal reflection. Nonfashion related descriptions seemed to be used mostly to cover "dead air" while others served to describe the emotional and/or physical state of the describer.

Other descriptions that were counted in this category were ones that provided transitional descriptions, such as when models were switching positions, as in "the next model is wearing...". These types of descriptions were usually not explicitly part of the description notes, but were implied by the order of the descriptions listed in them. Most of the blind and vision impaired live and webcast audience members stated that they liked having the additional descriptions as it added to their enjoyment of the show. Similar to the approach used in colour commentary, adding this type of personal commentary is encouraged and forms part of the announcer's stylistic character and ability to engage an audience.

The final category of commission variations was error misspeaks where the describer deviates from the intended meaning of her notes or states that something was incorrect. Thirteen percent of the commission variations (41 of 326 variations) were error misspeaks. Of these, 27 were verbally corrected while 14 were not corrected. An example of this type of variation was "widely beaded necklace, oh neckline!". One of the blind audience members commented that the quality of the description was good because the describer corrected her mistakes. This may have improved the describer's trustworthiness because she openly admitted to making an error and then corrected it giving the audience the impression that she wanted to be as accurate as possible. The audience was able to appreciate that there would be errors given that it was a live performance and there would be little opportunity to review descriptions and make error corrections as there is for television and film description. These types of errors also increased towards the end of the show perhaps indicating that the describer was becoming fatigued. In some theatres, such as the Royal Lyceum Theatre (Royal Lyceum Theatre, n.d.) and Vocal Eyes (Vocal Eyes, n.d.), two describers are used in an attempt reduce fatigue on the describers. In our case, the describer only performed for one show so she was able to rest following the show. However, where multiple shows are described during a particular run, fatigue may become a greater issue requiring the use of more than one describer for any one show.

Omission variations tended to increase slightly as the show progressed until about thirty-second collection where they peaked at the collection immediately following the "five most difficult collections" as identified by the describer (seven of 11 collection background notes were omitted for this collection and there were two other omissions for this one collection alone). It seems that the describer was experiencing some fatigue at this point due to the complexity of the previous collections; she gave a very large sigh of relief after completing the description for the five collections. Her fatigue was then likely reflected in her increased omissions. 
After this one collection, the number of omissions seemed to become fewer as indicated by the negative but not significant trend in correction of omission errors with collection order or presentation time.

Only 14 percent (18 out of 130) of omissions were complete omissions of a planned description. This type of omission most often occurred when the describer was rushed and this meant that only 18 of 187 (10 percent) outfits for which there was prepared description were omitted during the live show. Preparing to describe more than the intended number of outfits gave the describer the opportunity to omit collection notes and outfit descriptions if she was running out of time and/or wanted to add new pertinent commentary that was not within the description script. The describer was also able to use previously omitted collection notes later in between or at the end of a collection, which she did on six occasions. In addition, it was not necessary to prepare descriptions for every outfit saving the describer unnecessary preparation effort.

On several occasions, the omission of an outfit description and background notes seemed purely due to lack of time. During one of the collection descriptions, this problem was especially evident; the describer states: "Ah! I wish I had time to describe another one but I don't!". In a similar predicament, the describer initially thought that she had run out of time, but midway through stating this, was able to incorporate part of the omitted description by saying, "I didn't have time to describe that one, which is too bad because it has a really beautiful...dark denim open lapel, wide collar jacket that goes down to the waist".

The availability of the additional prepared information also provided the describer with a "description safety reserve", giving her the ability to prioritize descriptions and collection notes. For example, 19 percent of all omissions (25 out of 130) were unused notes where the describer omitted some of the introductory information that she made about each collection. The availability of additional description information may have also served to reduce the number of non-fashion related general improvisations as well.

Sixty-seven percent ( 87 out of 130 omissions) were words that were eliminated from the description notes of an outfit. These omission variations could have been intentional where the describer was making creative decisions based on timing or relevance of an item. There is, of course, the possibility that the describer inadvertently skipped over descriptions, words, or collection notes simply by mistake.

The describer's ability to spontaneously react to, and describe the action that was occurring on stage can be attributed, at least in part, to her education as a fashion and theatre student. Two of three live audience members and three of five blind or low-vision webcast audience members appreciated the describer's knowledge of fashion and reported that it positively affected their entertainment. The describer's training enabled her to improvise descriptions that were concise while serving to embellish those that were pre-planned: "[the outfits] are so extremely detailed; there are so many dozens of layers, multiple fabrics and shades".

The describer's theatrical training allowed her to improvise throughout the live performance, as she was aware that her prepared $\mathrm{AD}$ might not be representative 
of events occurring on stage. She made time to add pertinent information that she had not noticed before and, therefore, these descriptions were unscripted: "oh, and there's grey ruffled detailing that I didn't notice before". Similarly, the describer took into account what parts of outfits could not be seen by sighted audience members, incorporating it as part of the AD: “...a pink spandex bikini which you can't really see because it is under...". Two of the three blind and low-vision audience members watching the show live stated that one of the strengths of the AD was the level of detail that was relayed to them, including what the models were wearing and what was occurring on stage.

The describer's emotional delivery, no doubt indebted to her passion for fashion and theatre, seemed to play a factor in blind and low-vision and all of the sighted spectators enjoyment, all but one arguing that it was one of the strengths of the live event. Emphasizing the contextually relevant aspects of each collection, while simultaneously infusing her commentary with her emotional reaction to each collection, the describer was able to connect to her audience, catering to the experience of a fashion show.

The describer's emotional descriptions of the collections did hinder the enjoyment of one vision impaired and one sighted spectator who stated, "I just wanted the descriptions, no[thing] too emotional". It is not surprising that some spectators found the style of description to be a weakness because it is different from the conventional form of description on television. Almost all AD is stylistically very similar, occurring using third-person narration, the describer taking on a neutral presence outside of the narrative they describe. While more factual, neutral tone descriptions may actually be a preference, it may also be the result of what is familiar, comfortable, and trustworthy. Fels, et. al. (2006) have begun to explore the affects of describer style on the credibility of the description versus the entertainment value of it but much remains to be explored. Considerable research in different live and programmed domains remains to ascertain the impact of different description styles on audiences.

One blind spectator voiced concern with the describer's sight-centric terminology, preferring that the describer focus on her additional senses, saying "don't describe things in visual terms, find phrases, metaphors, think of other senses, textile, colour...super saturated...faded". The literature of the topic of communication between sighted and blind individuals seems to be in disagreement with this user's opinion, many blatantly addressing the issue of sighted terminology and encouraging its use (Blind Sport New Zealand Inc., 2001; American Foundation for the Blind, n.d.; Vision Australia, n.d.; US Department of Education - NIDRR, n.d.) Further research regarding sight-centric language and $\mathrm{AD}$ is required to address this issue.

One final issue of concern suggested by most of the audience members was the music volume for the show was too loud which made it difficult to hear the description through the headset, even with the volume controls on the headset. In this fashion show example, the house audio was not broadcast through the headset. In live performances where there is loud music such as in the fashion show and 
$\mathrm{AD}$ combined, people using the $\mathrm{AD}$ with wireless headsets should be seated away from the speakers so that the two audio sources do not interfere with each other. This usually means that people using AD should not be seated in the front row of the theatre - a place often reserved for people with disabilities.

\section{LIMITATIONS}

There are numerous limitations to this study but there are four important ones that will be elaborated here. The first limitation is that data was collected for a single show with live description and with a limited number of blind audience members (live and on-line). However, this was an exploratory study where we wanted to gain an understanding of the feasibility of using an emotive $\mathrm{AD}$ style for a live described event. We believe that even this limited quantity of data provides evidence of the audience reaction and sufficiency of providing an emotive description style.

Another limitation is that we did not measure workload or fatigue rates with an objective measure and thus have relatively poor predictors of this aspect of the live AD process. Future studies could use galvanic skin response and/or heart rate variability of the describer as physiological measures of workload/stress combined with a standard subjective cognitive workload instrument such as the NASA TLX (Hart and Staveland 1988). However, these studies should take into account the describer's experience and the potential for the describer to become mentally exhausted, especially when describing for long intervals. Therefore, it would not be surprising if the stress level is initially high. For this reason, we recommend that further studies measure the audio describer's stress level over several performances or, at least, account for the novelty factor of participating in a new activity. Measuring workload was not the focus of this study as we were attempting to examine the feasibility of the process and explore the types of description variations that arose.

Thirdly, we recommend that researchers and the describer meet to debrief after the project is completed. This would give researchers additional information about the process, understanding that it would vary by project and individual. It would be especially beneficial for researcher to go over the data with the describer, asking him or her to reflect upon commission and omissions.

A fourth limitation is that we did not measure the extent of the understanding that audience members gained or lost due to the description. Finding an appropriate instrument to measure understanding is difficult and the subject for future research. We suggest that using tests written by sighted researchers and administered after the completion of the event is inappropriate for the subject matter. In addition, we were most interested in the impact of the description and show on the entertainment value. Perhaps holding a focus group to discuss the collections and what was memorable with audience members (sighted and vision impaired) would provide some insight into people's levels of understanding and entertainment. However, the timing of collecting this data would be important. In our study, the entire show 
lasted about one hour and forty-five minutes including speeches and audience fatigue may interfere with people's ability to participate in a focus group immediately following the event. Waiting for another day to carry a focus group may result in a decay of people's ability to remember and identify with this fashion show.

\section{CONCLUSION}

In this study of a single audio described event, Mass Exodus fashion show, we examined how an emotional style of $\mathrm{AD}$ could be applied and the impact that style had on live and on-line audience members. In this study, we found that most audience members enjoyed the style of description and found that it added to the entertainment value of the show. Ten different types of variations were identified between the written notes prepared prior to the show and the actual AD produced during the show. However, the vast majority of those variations were additions to the script notes rather than omissions or changes to them. Finally, it appears that a description rate of about 60 percent seems appropriate and feasible for a fashion show where the only audio is music. We then suggest that using an emotional style of $\mathrm{AD}$ where the describer can introduce excitement and personal interest comments similar to that used in play-by-play sporting commentary is feasible and even desirable. In addition, live description of this style will have variations and mistakes because it is subjected to the organic nature of live events. However, using a subject matter expert such as the fashion expert used in our case will likely improve the quality and quantity of the live description. 


\section{REFERENCES}

American Federation for the Blind. Communicating Comfortably. Retrieved 13 November 2006 from http://www.afb.org/Section.asp?SectionID=36\&TopicID=163\&DocumentID $=194$. (n.d.)

Arts Access Incorporated. Arts Access. Retrieved 28 November 2006 from http://www.artsaccess.com.au/home (n.d.)

Arts and Visually Impaired Audiences. Audio Describer Criteria. Retrieved 14 August 2006 from http://www.artsvia.org/critera.html (n.d.)

Audio Description Associates. About Us. Retrieved 29 November 2006 from http://www.audiodescribe.com/training1.html (n.d.)

Audio Description International. What is Audio Description? Retrieved 28 November 2006 from http://adinternational.org/ADIad.html (2006)

Birmingham Hippodrome. Retrieved 28 November 2006 from http://www. birminghamhippodrome.com/?page $=63(2006)$

Blind Sport New Zealand, Inc. Relax!: A few pointers to help you feel at ease with blind people in day to day situations. Retrieved 27 November 2006 from http://www.blindsport.org.nz/relaxabc.pdf (2001)

Branje, C. Marshall, S., Tyndall, A., Fels, D.I., (2006) LiveDescribe. AMCIS 2006. Acapulco.

British Council for the Arts. Arts in Performance Profile: Extant. Retrieved 13 September 2006 from http://www.britishcouncil.org/arts-performance-in-profile-2006-extant.htm (n.d.)

Centerstage. Retrieved 28 November 2006 from http://www.centerstage.org/ page.php?pageID=51(n.d.)

Cumbernauld Theatre. Box Office. Retrieved 28 November 2006 from http://www. cumbernauldtheatre.co.uk/boxoffice.html\#access (2003)

Derby Playhouse Access. Retrieved on 9 August 2006 from http://www.derbyplay house.co.uk/access.html (n.d.)

English National Opera. Disabled Access. Retrieved 28 November 2006 from http://www.eno.org/visitors/disabled.php(n.d.)

Fels, D.I., Udo, JP, Diamond, J.E. \& Diamond J.I. (2006) A first person narrative approach to video description for animated comedy. Journal of Visual Impairment and Blindness 100 (5): 295-305.

Guthrie Theatre. Access Services for Blind or Visually Impaired. Retrieved 2 August 2006 from http://www.guthrietheater.org/GUIDETOGUTHRIE/AccessServices/ForPatrons whoarebrBlindorVisionImpaired/tabid/126/Default.aspx (n.d.)

Hansen, A.D. (1999) Narrating the Game: Achieving and Coordinating Partisanship in Real Time. Research on Language and Interaction 32 (3): 269-302.

Hart, S. G. \& Staveland, L.E. (1988) Development of NASA-TLX (Task Load Index): results of empirical and theoretical research. In Hancock, P.A. \& Meshkati N. (eds.) Human Mental Workload. Imprint, North-Holland, pp 139-183

Hedrick, T. (2000) The Art of Sportscasting: how to build a successful career. Diamond Communications, SouthBend. 
Hospital Audiences, Inc. Access for All-Preface. Retrieved 13 September 2006 from http://www.hospitalaudiences.org.database/a4a-pref.htm (n.d.)

Kennedy Centre for the Arts. Audio Described Performances. Retrieved 31 October 2007 from http://www.kennedy-center.org/accessibility/visual.html (n.d)

Mass Exodus: Open Concept (2006) Mass Exodus Fashion Show http://www.ryecast.ryerson .ca/dmpstreams/massexodus2006/index.asp

McGuire, J. (2002) Selective Perception and its Impact on the Evaluation of Radio Sports Play-By-Play Announcers. Journal of Radio Studies 9 (1): 51-64.

Metropolitan Washington Ear (n.d.) Audio Description. Retrieved 13 September 2006 from http://www.washear.org/audiod.htm

National Center for Accessible Media. Rich media accessibility. Retrieved 19 October 2004 from http://ncam.wgbh.org/richmedia/strategies/XAD.php (2003)

National Theatre. Accessibility for People with Disabilities. Retrieved 8 August 2006 from http://www.nationaltheatre.org/services/accessibility.html (n.d.)

Orange Tree Theatre. Access. Retrieved 13 September 2006 from http://www.jghonline. co.uk/orangetree/about_access.asp (n.d.)

Packer, J. \& Kirchner, C. Who's Watching? American Foundation for the Blind. Retrieved 15 November 2007 from http/www.empowermentzone.com/watching.txt (1997)

Peli, E., \& Fine, E. M. (1996) Evaluating visual information provided by audio description. Journal of Visual Impairment and Blindness 90(5): 378-385.

Pettitt, B., Sharpe, K., \& Cooper, S. (1996). AUDETEL: Enhancing television for visually impaired people. British Journal of Visual Impairment, 14 (2): 48-52

Pitlochry Festival Theatre. Access All Areas. Retrieved 29 November 2006 from http://www.pitlochry.org.uk/page32.php (n.d.)

Royal Court Theatre. Access for People with Disabilities. Retrieved 8 September 2006 from http://www.royalcourttheatre.com/supportdetail.asp?ArticleID=26 (n.d.)

Royal Lyceum Theatre Audio Description. Retrieved 8 September 2006 from http://www. lyceum.org.uk/sites/box/box04.html (n.d.)

Royal National Theatre. Disability Access Information. Retrieved 8 September 2006 from http://website-archive2.nt-online.org/?lid=1652 (n.d.)

Royal Shakespeare Company. Access Guide. Retrieved 28 November 2007 from http:// www.rsc.org.uk/downloads/pdfs/access_guide.pdf (2006)

Schmeidler, E., \& Kirchner, C. (2001). Adding audio description: Does it make a difference? Journal of Visual Impairment and Blindness 95 (4): 198-212.

Snyder, J. Audio Description: The Visual Made Verbal. Retrieved 25 November 2006, from http://www.audiodescribe.com/article1.html (2004)

Sutcliffe, A., \& Rugg, G. (1998). A taxonomy of error types for failure analysis and risk assessment. International Journal of Human-Computer Interaction, 10 (4): 381-405.

US Department of Education - NIDRR Effective Communication Techniques: Communicating with People who are Deaf or Hard of Hearing Retrieved 11 November 2006 from http://www.adaportal.org/Communication/communication-techniques.html (n.d.) 
Vision Australia. Communicating Effectively with People who are Blind or Low Impaired. Retrieved 13 November 2006 from http://www.visionaustrailia.org.au/info.aspx?Page $=822$ (n.d.).

Vocal Eyes. Who We Are. Retrieved 9 September 2006 from http://www.vocaleyes.co .uk/index.cfm?p=11796 (n.d.)

Wall, J. S. (2002). TV Broadcasting for All. Open Workshop on Standardization in the Field of Subtitling, Sevilla, Spain.

W3C. Web Content Accessibility Guidelines. Retrieved 28 November 2006 from http://www.w3.org/ TR/WAI-WEBCONTENT/ (1999).

W3C. Web Content Accessibility Guidelines - Working Draft. Retrieved 18 March 2008 from http://www.w3.org/TR/WCAG20/. 